\title{
Medical emergencies in the dental practice poster: revised and updated
}

\author{
Phil Jevon*1
}

\section{Key points}

'Medical Emergencies in the Dental Practice' and 'Emergency Drugs in the Dental Practice' posters are designed as an aide-memoire to manage medical emergencies in the dental practice.
Management and treatment revised reflecting current guidelines.
The new poster includes key emphasis on $A B C D E$ to assess and treat the acutely ill patient, as well as a new section covering red flag sepsis.

\begin{abstract}
Medical emergencies can occur in the dental practice. The posters 'Medical Emergencies in the Dental Practice' and 'Emergency Drugs in the Dental Practice' have been designed to help dental care professionals to respond effectively and safely to a medical emergency. They have been updated and completely revised in line with current national guidelines and recommendations. The 'Medical Emergencies in the Dental Practice' poster is available as an insert in this issue of the British Dental Journal. Both posters are available to download from https://www.bda.org/advice/ Pages/Patient-care.aspx.
\end{abstract}

\section{Introduction}

Members of the dental team have a duty of care to ensure they provide an effective and safe service to their patients. The satisfactory performance in a medical emergency in the dental practice has wide-ranging implications in terms of equipment, training, standards of care, clinical governance, risk management and clinical audit.

The revised and updated 'Medical Emergencies in the Dental Practice' poster is designed to be an aide-memoire to assist the dental team in safely and effectively managing medical emergencies.

The aim of this article is to provide a detailed overview of the revised and updated poster designed to help manage medical emergencies in the dental practice.

\section{General Dental Council and medical emergencies}

The General Dental Council (GDC) states: 'a patient could collapse on any premises at any time, whether they have received treatment or

${ }^{1}$ Academy Tutor, Walsall Teaching Academy, Manor Hospital, Walsall, UK.

*Correspondence to: Phil Jevon

Email address: phil.jevon@walsallhealthcare.nhs.uk

Refereed Paper

Accepted 22 May 2020

https://doi.org/10.1038/s41415-020-1789-y not. It is therefore essential that all registrants must be trained in dealing with medical emergencies, including resuscitation, and possess up to date evidence of capability.'

Planning ahead, there should be at least two people available within the working environment to deal with medical emergencies when treatment is scheduled to take place (in exceptional circumstances, the second person could be a receptionist or a person accompanying the patient). ${ }^{2}$

Members of the dental team must maintain their knowledge and competence to effectively and safely deal with a medical emergency, an important aspect of all dental professionals' continuing professional development (CPD). ${ }^{2}$

\section{Incidence of medical emergencies}

Medical emergencies that have occurred in dental practices include vasovagal syncope, angina, hypoglycaemia, epileptic seizures, choking, asthma, anaphylaxis and cardiac arrest. ${ }^{3}$ It is estimated that, on average, a general dental practitioner (GDP) will experience a medical emergency at least once every two years. ${ }^{4,5}$

Vasovagal syncope is the most common emergency encountered. ${ }^{3,4,5}$ Interestingly, one study showed that $4.8 \%$ of all GDPs observed $22 \%$ of all syncopes and that the prevalence of vasovagal syncope tends to decrease with professional experience. $^{5}$

\section{Risk management}

Risk management can play an important part in reducing the risk of medical emergencies in the dental practice. It is therefore recommended that all primary care dental facilities have a process for medical risk assessment of their patients. $^{6}$

Anticipation of potential medical emergencies that may arise should be highlighted by taking a thorough medical history which is revised, updated and checked each time the patient presents for treatment. ${ }^{7}$ It has been suggested that the presence of an updated medical history may help to minimise the risk of a medical emergency occurring. ${ }^{8}$

\section{National guidance on the management of medical emergencies}

The National Institute for Clinical Excellence's (NICE's) 'Medical Emergencies in Dental Practice' section of the British National formulary $(\mathrm{BNF})^{9}$ provides guidelines on the management of the more common medical emergencies which may arise in the dental practice.

Other specific guidance is provided by authoritative bodies including NICE, Addison's Disease Self-Help Group (adrenal crisis), British Thoracic Society (asthma), British Heart Foundation (cardiac emergencies), Epilepsy 
UK (epileptic seizures), Stroke Association (acute stroke), Diabetes UK (hypoglycaemia), UK Sepsis Trust (sepsis) and Resuscitation Council (UK) (anaphylaxis).

\section{'Medical Emergencies in the Dental Practice' poster}

The 'Medical Emergencies in the Dental Practice' A3 poster (Fig. 1) was first produced in 2009 as an aide-memoire to assist the dental team to safely manage medical emergencies occurring in the dental practice. ${ }^{10}$ It was subsequently updated and revised in $2012^{11}$ and 2015. ${ }^{12}$

The poster is intended to be placed on the wall in the surgery where it can be easily and quickly accessed should an emergency occur. The emergencies covered are listed in alphabetical order:

- Adrenal crisis

- Anaphylaxis asthma

- Cardiac emergencies

- Epileptic seizures

- Hypoglycaemia

- Red flag sepsis

- Stroke

- Syncope.

The important signs and symptoms to look out for to help correctly diagnose each emergency are listed, together with the principles of safe and effective treatment. Where appropriate, the recommended doses of drugs (including paediatric doses) and routes of administration are also stated.

This poster is included as an insert in this issue of the British Dental Journal. Further copies can be downloaded from https://www. bda.org/advice/Pages/Patient-care.aspx.

\section{Summary of updates and revisions}

\section{Adrenal crisis}

A 2013 UK survey of steroid-dependent patients found that $8 \%$ had developed adrenal crisis while undergoing a dental procedure. ${ }^{13}$ The NHS Specialist Pharmacy Service ${ }^{14}$ has recently published guidance regarding what steroid supplementation is required to prevent adrenal crisis in a patient with primary adrenal insufficiency (for example, Addison's disease) undergoing a dental procedure:

- Minor dental procedures (for example, scale and polish, replacement filling) advise the patient to take an additional oral dose of glucocorticoid one hour before their appointment
- More complex dental procedures (for example, root canal work under local anaesthetic) - prescribe steroid supplementation before the procedure and for a full 24 hours afterwards

- Dental extractions and minor oral surgery - refer to secondary care.

Patients with primary adrenal insufficiency should be advised to bring their emergency hydrocortisone injection kit to all dental appointments, ${ }^{14}$ as well as their personalised adrenal crisis letter which provides medical treatment guidance. ${ }^{13,15}$

If the patient develops adrenal crisis, call 999 immediately, ${ }^{15}$ stating 'Addisonian crisis', ${ }^{13}$ and if the patient's emergency hydrocortisone injection kit is available, administer intramuscular (IM) hydrocortisone. The recommended dose, which should be stated on the patient's adrenal crisis letter, depends on the patient's age: ${ }^{15}$

- Adults: $100 \mathrm{mg}$

- Children six years of age or older: $50-100 \mathrm{mg}$ (use clinical judgement depending on the age and size of the child)

- Children one to five years of age: $50 \mathrm{mg}$

- Infants up to one year of age: $25 \mathrm{mg}$.

\section{Anaphylaxis}

Some dental practices stock adrenaline autoinjectors (AAIs) in their medical emergency drugs kit, so the following issues need to be highlighted.

There have been ongoing supply issues relating to AAIs, which led to the Medicines and Healthcare products Regulatory Agency (MHRA) approving the extension of expiry dates beyond the labelled expiry date by four months for specific batch numbers of Epipen $300 \mathrm{mcg}$, Jext $150 \mathrm{mcg}$ and Jext $300 \mathrm{mcg}$ AAI devices. ${ }^{16,17}$ It is recommended to periodically check the viewing window in the label of the AAI device, to ensure the liquid inside is still clear and colourless; if discoloured, the device should not be used. ${ }^{17}$ It is also advised to sign up to the Expiry Alert Service provided by the specific AAI manufacturer's website. ${ }^{17}$

The above supply issues led to the Chief Dental Officer for England requesting dental practices that stock AAIs in their medical emergencies drug kit to renew them with adrenaline ampoules, in order to preserve national stocks of the devices: 'all healthcare professionals providing services where anaphylaxis treatment may be required should have the competency to draw up and administer adrenaline from ampoules with a normal syringe and needle. ${ }^{18}$
Problems have been reported to the MHRA concerning Emerade AAIs failing to activate and adrenaline not being administered, possibly relating to how much force is applied to the device. ${ }^{19}$ The issue is currently being investigated by the manufacturer. There has also been a recent recall of Emerade $300 \mathrm{mcg}$ AAIs due to an error in one component of the auto-injector, believed to cause some devices to fail to activate and deliver adrenaline. ${ }^{19}$

Following the tragic death of Natasha Ednan-Laperouse (anaphylaxis due to allergy to sesame seeds in a baguette), the coroner reported his concerns to MHRA regarding the length of the needle $(16 \mathrm{~mm})$ and the dose of adrenaline $(300 \mathrm{mcg})$ in adult Epipen AAIs, when the Resuscitation Council (UK) actually advises $25 \mathrm{~mm}$ needle length and adrenaline $500 \mathrm{mcg}$ (for adults). ${ }^{20}$

The Resuscitation Council (UK) $)^{21}$ has since reiterated that:

- The recommended needle length for IM injections is $25 \mathrm{~mm}$ (a blue 23G $25 \mathrm{~mm}$ needle) for all ages to ensure that the drug is injected into the muscle; a longer $21 \mathrm{G} 38$ $\mathrm{mm}$ needle may be needed in some adults. ${ }^{22}$ This guidance is based on recommendations from Public Health England (PHE) ${ }^{23}$

- In anaphylaxis, healthcare professionals should be administering the recommended dose of adrenaline for a patient over 12 years of age, which is $500 \mathrm{mcg}$

- An AAI should only be used if it is the only available adrenaline preparation when treating anaphylaxis in a healthcare setting.

Dental practices should therefore ensure that they have adrenaline $1: 1000(1 \mathrm{mg} / \mathrm{ml})$ ampoules in their emergency drugs kit. ${ }^{21,24}$ It would also be reasonable to follow PHE guidelines ${ }^{23}$ for anaphylaxis packs and stock:

- Adrenaline 1:1000 ampoules x 2

- Blue 23G $25 \mathrm{~mm}$ needles x 4

- Graduated $1 \mathrm{ml}$ syringes x 4 .

Adrenaline 1:1000 (1 mg/ml) pre-filled syringes are also available ${ }^{9}$ and are preferred by some to negate the need to draw up from an ampoule, ${ }^{25}$ though there are currently supply issues with this device as well. Although an AAI, Emerade $500 \mathrm{mcg}$ (if available) can also be used because the needle length is adequate $(24 \mathrm{~mm})$ and the dose is the recommended dose (paediatric Emerade AAIs are also available). The decision whether or not to use Emerade would need to be determined locally. ${ }^{26}$ 


\section{MEDICAL EMERGENCIES IN THE DENTAL PRACTICE}

\begin{tabular}{|c|c|c|}
\hline $\begin{array}{c}\text { MEDICAL } \\
\text { EMERGENCY }\end{array}$ & SIGNS \& SYMPTOMS & MANAGEMENT \\
\hline Adrenal crisis & $\begin{array}{ll}\otimes & \text { Collapse; pallor, cold \& clammy skin } \\
囚 & \text { Hypotension \& dizziness } \\
\bigotimes & \text { Vomiting \& diarrhoea }\end{array}$ & $\begin{array}{l}\text { Airway Breathing Circulation Disability Exposure } \\
\text { Call 999, state "Addisonian crisis", SBAR } \\
\text { Lie flat; administer oxygen } 15 \text { litres/min } \\
\text { Patient's hydrocortisone emergency IM kit at hand: hydrocortisone 100mg IM. }\end{array}$ \\
\hline Anaphylaxis & 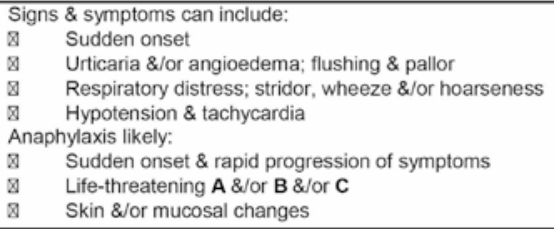 & $\begin{array}{l}\text { Airway Breathing Circulation Disability Exposure } \\
\text { Call } 999 \text {, state "Anaphylaxis", SBAR } \\
\text { Lie flat, elevate legs (if breathing not impaired); administer oxygen } 15 \text { litres } / \mathrm{min} \\
\text { Administer adrenaline } 500 \text { micrograms IM }(0.5 \mathrm{ml} \text { of } 1: 1000) \\
\text { Repeat adrenaline at } 5 \text { minute intervals until an adequate response } \\
\text { Paediatric doses of adrenaline: } \\
<6 \text { yrs }-150 \text { micrograms }(0.15 \mathrm{ml} \text { of } 1: 1000) ; 6-12 \text { yrs - } 300 \text { micrograms }(0.3 \mathrm{ml} \text { of } \\
1: 1000) ;>12 \text { yrs - } 500 \text { micrograms }(0.5 \mathrm{ml} \text { of } 1: 1000)\end{array}$ \\
\hline Asthma & 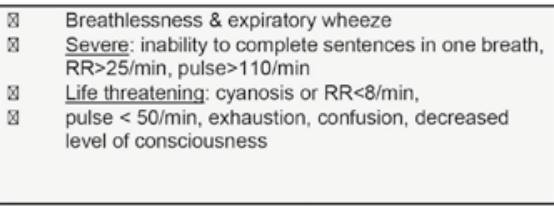 & $\begin{array}{ll}\otimes & \text { Airway Breathing Circulation Disability Exposure } \\
\otimes & \text { Sit upright; if available, follow patient's personalised asthma action plan (PAAP) } \\
\otimes & 2 \text { puffs (100 micrograms/puff) } \beta 2 \text { bronchodilator inhaler e.g. salbutamol; repeat } \\
\text { doses may be necessary (early use of spacer device) }\end{array}$ \\
\hline $\begin{array}{c}\text { Cardiac } \\
\text { Emergencies }\end{array}$ & $\begin{array}{l}\text { Symptoms can vary but commonly: } \\
\text { Chest pain or discomfort that suddenly occurs and } \\
\text { doesn't go away. It may feel like pressure, squeezing } \\
\text { or heaviness in your chest } \\
\text { Pain that may spread to your left or right arm or may } \\
\text { spread to your neck, jaw, back or stomach } \\
\text { Feeling sick, sweaty, light-headed or short of breath } \\
\text { NB: Heart attacks in women commonly missed }\end{array}$ & $\begin{array}{l}\otimes \quad \text { Airway Breathing Circulation Disability Exposure } \\
\otimes \quad \text { Call } 999 \text {, state "heart attack", SBAR } \\
\otimes \quad \text { Comfortable position (usually sitting up) } \\
\otimes \quad \text { GTN spray } 400-800 \mathrm{mcg} \text { (typically1-2 activations) sub lingual } \\
\otimes \quad \text { Dispersible aspirin } 300 \mathrm{mg} \text { to chew (unless there is clear evidence of allergy to it) } \\
\text { NB Known angina: sit down, rest, GTN; no relief after a few minutes repeat GTN. Still no } \\
\text { relief after a few minutes } \rightarrow \text { heart attack protocol: call } 999, \text { SBAR \& aspirin (see above) }\end{array}$ \\
\hline Epileptic seizures & $\begin{array}{l}\text { Sudden collapse \& loss of consciousness } \\
\text { Rigidity \& cyanosis } \\
\text { Jerking movements of limbs } \\
\text { Noisy breathing } \\
\text { Tongue may be bitten } \\
\text { Frothing at mouth } \\
\text { Incontinence may occur }\end{array}$ & 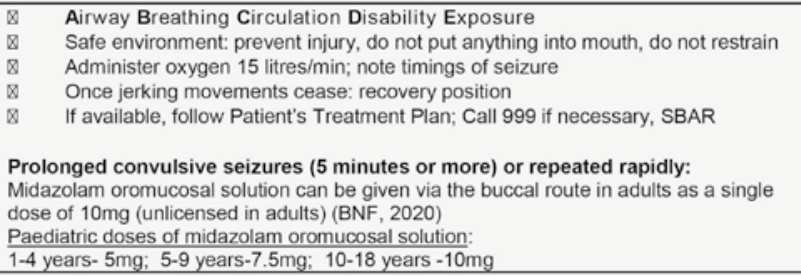 \\
\hline Hypoglycaemia & $\begin{array}{l}\text { Shaking/trembling } \\
\text { Slurred speech \& vagueness } \\
\text { Sweating \& pallor; blurred vision } \\
\text { Tiredness/Lethargy } \\
\text { Confusion/aggression } \\
\text { Stroppy/moody } \\
\text { Unconsciousness }\end{array}$ & 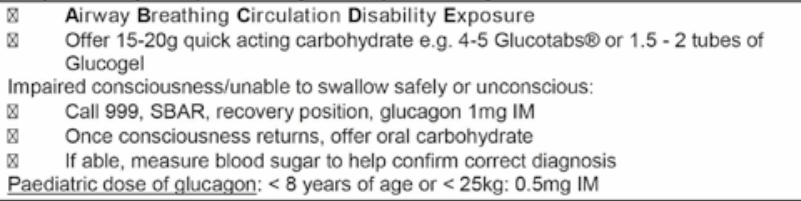 \\
\hline Red Flag Sepsis &  & 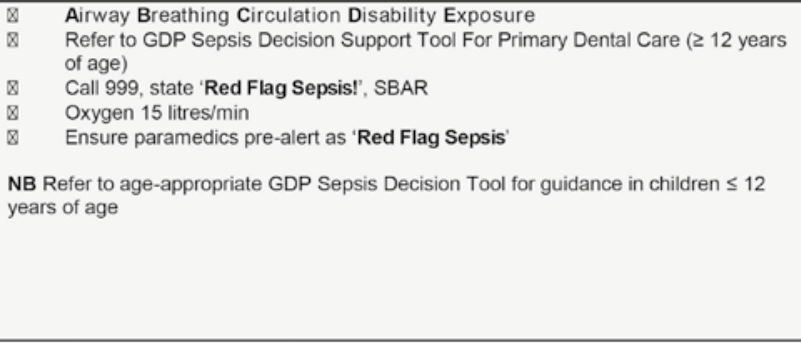 \\
\hline Stroke & $\begin{array}{l}\frac{\text { Facial weakness }}{\text { Arm weakness }} \\
\text { Speech problems } \\
\text { Time to call } 999 \\
\end{array}$ & $\begin{array}{l}\text { Airway Breathing Circulation Disability Exposure } \\
\text { Act FAST \& call 999; SBAR } \\
\text { Administer oxygen } 15 \text { litres/min } \\
\text { Nil by mouth; appropriate position }\end{array}$ \\
\hline Syncope & $\begin{array}{l}\text { Feels faint/dizzy/light headed } \\
\text { Collapse \& loss of consciousness } \\
\text { Pallor, sweating, slow pulse, low BP } \\
\text { Nausea/vomiting }\end{array}$ & $\begin{array}{l}\text { Airway Breathing Circulation Disability Exposure } \\
\text { Lie flat, elevate legs \& loosen tight clothing; oxygen? (not usually necessary) } \\
\text { Once consciousness returns, offer glucose in water or sweet tea } \\
\text { Slow recovery: consider alternative diagnosis; unresponsive: check signs of life }\end{array}$ \\
\hline
\end{tabular}

\section{References}

Addison's Self Help Group (2020) Adrenal Crisis Can Kill unww addisonsdisease org uk accessed 20/04/20 BNF (2020) Prescribing in dental practice unww.bnf.nice.org.uk accessed 20/04/20 British Heart Foundation (2020) Heart Attack umw bhf ora uk accessed 20/04/20 BTS/SIGN (2019) 158 British guideline on the management of asthma wmw.brit-thoracic.org.uk accessed 20/04/20 CQC (2019) Dental mythbuster 4: Drugs \& equipment for a medical emergency www. cac. org uk accessed 20104/20 CQC (201) Dentar Jevon P (2021) Medical Emergencies in the Dental Practice $3^{\text {tis }} \mathrm{Ed}$.Wiley Blackwell, Oxford Jevon P (2021) Medical Emergencies in the Dental Practice $3^{\text {to }}$ Ed_Wiley Blackwell, Oxford
NICE (2020) Epilepsies: diagnosis and management wwwwice. org uk (accessed 20/04/20) RC (UK) (2018) Primary Dental Care-Quality standards for CPR \& training www. resus. org.uk accessed 20/04/20 Stroke Association (2020) Act FAST unww stroke org uk accessed 20/04/20 Poster designed as an aide mémoire by Phil Jevon
Medical Education, Manor Hospital, Walsall, UK

Acknowledgements Dr R Daniels BEM UK Sepsis Trust (sepsis section); Mr N Rashid/Miss R Joshi, ED Consultants \& Mrs S Church Consultant Orthodontist

WALSALL HEALTHCARE NHS TRUST MAY 2020

\section{Fig. 1 'Medical Emergencies in the Dental Practice' poster}


If an AAI is used to treat anaphylaxis, it is important that the user adheres to the manufacturer's guidelines for its use, taking particular care to avoid accidental selfinjection, which has been reported. ${ }^{27}$

$\mathrm{NICE}^{28}$ has revised its guidelines for the treatment of anaphylaxis; there are two important subtle changes:

- Repeat IM adrenaline at five-minute intervals until there has been an adequate response replaces no improvement and according to the patient's response

- IM adrenaline - anterolateral aspect of the middle third of the thigh (ideally) or arm, depending on access. Previously, the arm has not been advised, but clearly there may be situations when the thigh (ideal route) is not practical or indeed not possible, particularly in a dental practice, in which case the arm is advocated.

\section{Asthma}

Deaths from asthma attacks are the highest they have been in the last decade and have increased by more than $33 \%$ over the last ten years. ${ }^{29}$ In 2018 in the UK, there were over 1,400 asthma-related deaths, an increase of $8 \%$ on 2017 figures. ${ }^{29}$ It is estimated that twothirds of asthma-related deaths could have been prevented by better basic care. ${ }^{30}$

The latest guidelines for the management of acute asthma in the dental practice ${ }^{31}$ in particular stress the importance of:

- The early use of a spacer device (Fig. 2). The salbutamol (beta-2 agonist) inhaler should be administered via the spacer one puff at a time, inhaled separately using



Fig. 2 Spacer device tidal breathing; according to response, give another puff every 60 seconds up to a maximum of ten puffs. ${ }^{31}$ Practically, in the dental practice, the patient would use their inhaler first while the surgery's spacer device is fetched

- Following the patient's own written personalised asthma action plan (if available). The patient should be advised to always have this with them and it should be followed in the event of an asthma attack in the dental practice.

A patient safety alert from the MHRA ${ }^{32}$ has highlighted the potential risk of choking when using a pressurised metered-dose inhaler (pMDI), where patients have inhaled the pMDI's mouthpiece cover or objects that have been entrapped in the pMDI (for example, a coin) into the back of the pharynx, resulting in coughing and in some cases aspiration, causing airway obstruction. Dental staff must be aware of the correct technique when using an inhaler. ${ }^{32}$

\section{Cardiac emergencies}

The standard management of a patient who is suspected of having a heart attack outside hospital has been revised:

- Call 999 immediately. ${ }^{33}$ Concerns have been raised regarding the significant drop in heart attack patients calling 999 or going to the emergency department during the current coronavirus (COVID-19) outbreak

- Ask the patient to chew dispersible aspirin $300 \mathrm{mg}^{34}$ (the alternative option of offering crushed aspirin to the patient is no longer advocated). Some dental practices stock enteric-coated aspirin $75 \mathrm{mg}$ or $300 \mathrm{mg}$, or aspirin $75 \mathrm{mg}$ tablets for this purpose dispersible aspirin $300 \mathrm{mg}$ tablets are what is advised. ${ }^{9}$

It is particularly important to be vigilant with women who may be having a heart attack: $:^{35}$

- There is a common misconception that coronary heart disease and heart attack are men's diseases, yet 35,000 women are admitted to hospital following a heart attack in the UK each year

- It is commonly thought that men and women experience different symptoms when having a heart attack; while symptoms vary from person to person, there are no symptoms that women experience more or less often than men

- Women may be less likely to seek medical attention and treatment quickly, despite the warning signs. This can significantly adversely affect prognosis
- A woman is $50 \%$ more likely than a man to receive the wrong initial diagnosis for a heart attack. Many of the 380,000 female heart attack survivors living in the UK today are living with heart failure as a consequence of their heart attack. The longer a heart attack is left undiagnosed and untreated, the more the myocardium can be irreversibly damaged

- Risk factors for heart disease increase the likelihood of a heart attack in women far more then in men; for example, smoking increases women's heart attack risk 100\% more than men's, hypertension $80 \%$ more and type 2 diabetes $50 \%$ more.

NICE has reiterated the importance of not routinely administering oxygen in a suspected heart attack. ${ }^{36}$ However, if the patient is hypoxaemic, adjust the oxygen flow rate to achieve a target oxygenation saturation ( $\mathrm{SpO} 2)$ of $94-98 \%$ (or $88-92 \%$ in patients with chronic obstructive pulmonary disease). ${ }^{36}$

Patients with known angina who experience chest pain are advised by the British Heart Foundation $^{37}$ to sit down, rest and use their own glyceryl trinitrate (GTN). If there is no relief after a few minutes, then repeat the GTN. If there is still no relief, call 999 and follow the heart attack protocol including aspirin (see above).

\section{Epileptic seizures}

$\mathrm{NICE}^{38}$ has updated its guidelines on the management of epileptic seizures. The following are stressed:

- All patients with epilepsy should have a personalised care plan, which should be brought to every dental appointment and should be followed if the patient has an epileptic seizure

- Buccal (oromucosal) midazolam is advised for prolonged (lasting five minutes or longer) or repeated seizures (more than three in an hour) in the dental practice.

Buccal (oromucosal) midazolam is available in the UK: ${ }^{39}$

- Buccolam contains midazolam hydrochloride $5 \mathrm{mg} / 1 \mathrm{ml}$ in pre-filled oral syringes of $2.5 \mathrm{mg}, 5 \mathrm{mg}, 7.5 \mathrm{mg}$ and $10 \mathrm{mg}$

- Epistatus contains midazolam maleate 10 $\mathrm{mg} / 1 \mathrm{ml}$. It is a preparation in a $5 \mathrm{ml}$ bottle with four oral syringes in the packaging. Epistatus is also available as pre-filled oral syringes of $2.5 \mathrm{mg}, 5 \mathrm{mg}, 7.5 \mathrm{mg}$ and $10 \mathrm{mg}$. This is an unlicensed product, available as a 'special'. 




Fig. 3 GlucaGen HypoKit (glucagon)

Buccolam pre-filled syringes have a red protective cap on the end of the syringe, which should be removed before administration of the drug. Removing this should also remove the translucent tip-cap underneath it, but occasionally they do not come off together, a problem highlighted in an MHRA patient safety alert. ${ }^{40}$ If the tip-cap is still in place, it will stop the medicine coming out of the syringe, and if the plunger is pushed harder, the tip-cap itself could fall off and land in the patient's mouth, where it will pose a choking risk. When the red protective cap is removed, always check that the tip-cap has been removed as well. ${ }^{39,40}$

\section{Hypoglycaemia}

The latest NICE guidelines on the management of diabetes now include the importance of being particularly alert in patients with impaired awareness of hypoglycaemia (IAH). ${ }^{41}$ IAH, an acquired syndrome associated with insulin treatment, results in the warning symptoms of hypoglycaemia becoming diminished in intensity, altered in nature or lost altogether. ${ }^{42}$ The prevalence of IAH increases with duration of diabetes and is much more common in type 1 than in type 2 diabetes. ${ }^{42}$ It is important to check medical history and ask the patient.

The treatment of hypoglycaemia in the dental practice has not changed. If the patient is conscious and cooperative, offer the patient 15-20 g of quick-acting carbohydrate; for example, 5-7 Dextrosol tablets, 4-5 Glucotabs, one bottle $(60 \mathrm{ml})$ Glucojuice or $150-200 \mathrm{ml}$ pure fruit juice. ${ }^{42}$ Chocolate is no longer recommended for the treatment of hypoglycaemia because its fat content slows the absorption of quick-acting carbohydrate..$^{42}$
It is important to be aware that, since the introduction of the Soft Drinks Industry Levy (SDIL) or 'sugar tax ${ }^{\text {'43 }}$ in 2018, some products (for example, Lucozade) do not contain sufficient carbohydrate and are no longer recommended to treat hypoglycaemia.

Glucagon is still advised if the patient is unable to have oral quick-acting carbohydrate. However, there has been some confusion concerning the storage of GlucaGen HypoKit (Fig. 3) (the commonest glucagon product currently in use in the UK), which has prompted the Care Quality Commission (CQC) to provide guidance on safe practice. ${ }^{44}$ To clarify, GlucaGen HypoKit can be stored:

- At a temperature of $2-8{ }^{\circ} \mathrm{C}$ (in a refrigerator), but it must not be frozen. The expiry date is what is written on the container (typically anything up to 36 months' shelf life)

- Outside the refrigerator at a temperature not exceeding $25{ }^{\circ} \mathrm{C}$ for 18 months, provided that the expiry date on the container is not exceeded. It should be stored in the original container and protected from light. This is common practice as it needs to be easily accessible for emergency use. The dental practice must be able to demonstrate that it has not exceeded 18 months of being stored outside the refrigerator (assuming this hasn't resulted in the expiry date on the box being exceeded) by having either a written record of when it was taken out of the refrigerator or having a copy of the invoice indicating the date of purchase. ${ }^{44}$

\section{Red flag sepsis}

Odontogenic infection-related sepsis is uncommon, but cases have been reported. ${ }^{45,46}$ Deaths from sepsis due to odontogenic infection are extremely rare, but they have been reported. ${ }^{47}$ It is also possible that a patient could have non-dental infection-related sepsis.

Early recognition and prompt effective treatment of sepsis improves outcomes and NICE requires dental team members to be trained in identifying people who may have sepsis. ${ }^{48}$ The key message has to be that the dental team must stop and think whether it could be sepsis in any patient who presents with signs or symptoms that indicate possible infection. ${ }^{49}$

The UK Sepsis Trust has developed three age-specific sepsis decision support tools to help the dental team identify and appropriately manage patients with suspected sepsis. These sepsis decision tools should be easily accessible in the dental practice.

The UK Sepsis Trust's definition of red flag sepsis identifies a set of easy-to-identify clinical parameters - the presence of one which, in the context of infection, identifies sepsis with a high risk of death and requires urgent treatment and transfer to hospital. ${ }^{50}$

\section{Stroke}

NICE's updated guidelines on the management of stroke still recommends the FAST approach to assess someone with a suspected stroke outside hospital. ${ }^{51}$ The Stroke Association ${ }^{52}$ has simplified the FAST approach (Fig. 4).

There is also a common misconception that patients with a suspected stroke should be given aspirin pre-hospital. NICE ${ }^{51}$ has reiterated that aspirin should not be given pre-hospital; it may be prescribed in hospital following a stroke caused by a blood clot (acute ischaemic stroke), but only once a diagnosis of intracerebral haemorrhage has been excluded by a brain scan. 


\section{Oxygen therapy}

Oxygen is often administered in a medical emergency. Modern oxygen cylinders commonly have an integral valve which needs to be open, as well as having to select the appropriate oxygen flow rate, for oxygen to flow and be administered to the patient. ${ }^{53} \mathrm{~A}$ recent patient safety alert highlighted that, in a three-year period, over 400 incidents involving incorrect operation of oxygen cylinder controls had been reported to the National Reporting and Learning System (NRLS), resulting in oxygen not flowing from the oxygen cylinder in an emergency situation. ${ }^{54} \mathrm{~A}$ number of patients suffered harm as a result.

Dental team members need to be familiar with and follow the manufacturer's instructions to operate their emergency oxygen cylinder, particularly relating to opening the integral valve (Fig. 5) before use. ${ }^{55}$

\section{SBAR communication tool}

NHS Improvement ${ }^{56}$ recommends the SBAR communication tool for use in healthcare settings:

- Situation

- Background

- Assessment

- Recommendation.

SBAR is an easy-to-use and structured communication tool that enables information

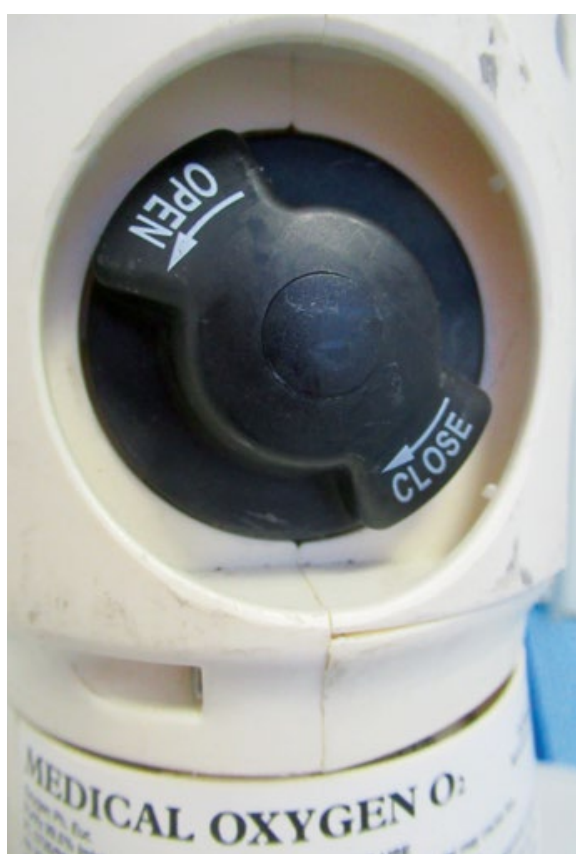

Fig. 5 An example of an integral valve on an oxygen cylinder

\section{Act FAST and call 999.}

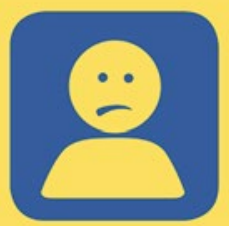

Facial weakness

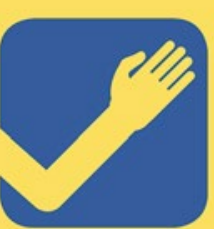

Arm

weakness



Speech problems



Time

to call 999

Fig. 4 Act FAST poster (reproduced with kind permission of the Stroke Association) ${ }^{52}$

to be accurately transferred between individuals. ${ }^{56}$ Originally developed by the United States military for communication on nuclear submarines, it has been successfully incorporated into a variety of clinical settings, particularly relating to improving patient safety in the setting of acute illness and calling for help.

SBAR can be used in any setting, but can be particularly effective in reducing the barrier to effective communication across different disciplines and between different levels of staff. ${ }^{56}$ In the dental practice setting, for example, it can help in a medical emergency to ensure effective communication when calling 999 for an ambulance.

\section{'Emergency Drugs in the Dental Practice' poster}

The 'Emergency Drugs in the Dental Practice' A4 poster (Fig. 6) was first produced in $2012^{11}$ and then revised in $2015 .{ }^{12}$ It is designed as an aide-memoire to assist the dental team to safely administer medications in a medical emergency and is designed to be kept in the emergency drugs box for quick reference. The poster has been revised in line with current guidelines and terminology, and can be downloaded from...

\section{Equipment and drugs for medical emergencies}

The Resuscitation Council (UK) ${ }^{6}$ provides guidance on what resuscitation equipment, including oxygen, dental practices should have. It is advised that the responsibility for checking resuscitation equipment is designated to named individuals, including reliable arrangements for cover in case of absence, with the frequency of checks depending upon local circumstances (but should be at least weekly). ${ }^{6}$
NICE provides guidance on what medications should be available for medical emergencies. Weekly checks of expiry dates for emergency medicines and availability of oxygen are advised. ${ }^{24}$

A practice could be in a difficult position from a medico-legal point of view if a patient came to harm during dental treatment due to a lack of the emergency resuscitation equipment recommended by the Resuscitation Council (UK) or medical emergency drugs recommended by NICE in the dental section of the BNF.9 These recommendations are upheld by the CQC. ${ }^{24}$

GDPs must consider what resuscitation equipment and medical emergency drugs will be needed (if any) when carrying out domiciliary dental treatment. It is important to undertake a full risk assessment to include medical risks posed by the patient's medical history and the suitability of the place where the treatment is to be carried out. ${ }^{57,58}$ The risk assessment tool developed by the British Society for Disability and Oral Health ${ }^{57}$ has been suggested. ${ }^{58}$

\section{Infection control}

The current COVID-19 outbreak has emphasised the need for adequate infection control measures, the principles of which still of course apply in a medical emergency setting. Hand hygiene is an integral part of preventing infection in a dental practice and the dental team has a duty of care to ensure it is managed in accordance with current guidelines. ${ }^{59,60,61}$

The Resuscitation Council (UK) recommends level 3 personal protective equipment (PPE) before starting chest compressions and ventilations in the dental practice in a patient with, or suspected to have, COVID-19. ${ }^{62}$ In the difficult position where 


\section{BDA EMERGENCY DRUGS IN THE DENTAL PRACTICE \\ Walsall Healthcare WHS \\ NHS Trust}

\begin{tabular}{|c|c|c|c|}
\hline DRUG & INDICATION & ADULT DOSE \& ROUTE & PAEDIATRIC DOSES \& ROUTE \\
\hline Adrenaline & Anaphylaxis & $\begin{array}{l}500 \text { micrograms }(0.5 \mathrm{mls} 1: 1000) \mathrm{IM} \\
\text { May be repeated at } 5 \text { minute intervals until an } \\
\text { adequate response }\end{array}$ & $\begin{array}{l}<6 \text { yrs: } 150 \text { micrograms }(0.15 \mathrm{mls} 1: 1000) \text { IM } \\
6-12 \text { yrs: } 300 \text { micrograms }(0.3 \mathrm{mls} 1: 1000) \text { IM } \\
>12 \text { yrs: } 500 \text { micrograms }(0.5 \mathrm{mls} 1: 1000) \text { IM } \\
\text { May be repeated at } 5 \text { minute intervals until an adequate response }\end{array}$ \\
\hline $\begin{array}{l}\beta 2 \text { bronchodilator (e.g. } \\
\text { salbutamol) inhaler }\end{array}$ & Asthma attack & $\begin{array}{l}2 \text { actuations inhaled } \\
\text { Use space device if necessary } \\
\text { Repeat doses may be necessary }\end{array}$ & $\begin{array}{l}\text { Dose as for adults. } \\
\text { Spacer device recommended }\end{array}$ \\
\hline $\begin{array}{l}\text { Glyceryl Trinitrate } \\
\text { Spray }\end{array}$ & $\begin{array}{l}\text { Angina or } \\
\text { suspected heart attack }\end{array}$ & $\begin{array}{l}2 \text { actuations sublingually; } \\
\text { May be repeated }\end{array}$ & N/A \\
\hline Dispersible Aspirin & Suspected heart attack & $300 \mathrm{mg}$ oral (chewed) & N/A \\
\hline Glucose (quick acting) & $\begin{array}{l}\text { Hypoglycaemia (patient cooperative } \\
\& \text { able to } \\
\text { swallow safely) }\end{array}$ & $\begin{array}{l}15-20 \mathrm{~g} \text { quick acting glucose e.g. } 1.5-2 \text { tubes } \\
\text { of Glucogel } \circledast \text { or } 4-5 \text { Glucotabs } \Theta\end{array}$ & Dose as for adults \\
\hline Glucagon & $\begin{array}{l}\text { Hypoglycaemia (patient unable to } \\
\text { swallow safely e.g. unconscious) }\end{array}$ & $1 \mathrm{mg} \mathrm{IM}$ & $\begin{array}{l}<8 \text { yrs }(<25 \mathrm{~kg}): 0.5 \mathrm{mg} \mathrm{IM} \\
>8 \mathrm{yrs}(>25 \mathrm{~kg}): 1 \mathrm{mg} \mathrm{IM}\end{array}$ \\
\hline $\begin{array}{l}\text { Midazolam oromucosal } \\
\text { solution }\end{array}$ & $\begin{array}{l}\text { Prolonged convulsive } \\
\text { seizures }(\geq 5 \text { mins) or } \\
\text { repeated ( } \geq 3 \text { in one hour) }\end{array}$ & $\begin{array}{l}\text { Midazolam oromucosal solution can be given } \\
\text { by the buccal route in adults as a single dose } \\
\text { of } 10 \mathrm{mg} \text { [unlicensed] }\end{array}$ & $\begin{array}{l}1-<5 \text { yrs: } 5 \mathrm{mg} \\
5-<10 \text { yrs: } 7.5 \mathrm{mg} \\
10 \text { to }<18 \text { yrs: } 10 \mathrm{mg}\end{array}$ \\
\hline
\end{tabular}

References

BNF (2020) Prescribing in dental practice umw. bnf.nice. org. uk accessed 05/04/20

only level 2 PPE is available, then placing a towel over the patient's nose and mouth while performing chest compression-only $\mathrm{CPR}$ is something to consider. ${ }^{62}$ The guidance relating to PPE is changing on a regular basis, and it is important to undertake regular risk assessments and keep up-to-date with current guidelines to help ensure the safety of members of the dental team (as well as others, including patients).

\section{Training in medical emergencies}

All dental staff should be trained and should receive regular updates on the management of medical emergencies; they should also possess up-to-date evidence of capability. ${ }^{1}$ Running regular mock scenarios/drills themed around medical emergencies involving a team approach is advised. ${ }^{1}$ From the author's experience, some surgeries find it helpful to use the poster in the training session to increase familiarity in its use. Ensuring the dental team is kept up-to-date in the management of medical emergencies is essential. ${ }^{6}$
The GDC has identified medical emergencies and CPR as an example of CPD content for development outcome C: 'Maintenance and development of knowledge and skill within your field(s) of practice. ${ }^{63}$

It is recommended that dental team members undertake at least ten hours in every CPD cycle and at least two hours of CPD on this topic every year. ${ }^{64}$ The team should carry out practice sessions throughout the year. These should be documented and areas of learning addressed. ${ }^{65}$

\section{Conclusion}

Every dental practice has a duty of care to ensure that an effective and safe service is provided for its patients. This article has provided an overview of the updated posters designed to help manage medical emergencies in the dental practice.

\section{Acknowledgements}

The author is grateful to Mr N. Rashid and Miss

R. Joshi (ED Consultants) and Mrs S. Church

(Consultant Orthodontist, Manor Hospital, Walsall,
$U K)$ for providing expert advice regarding the content of the poster, and to Dr R. Daniels BEM, UK Sepsis Trust, for his expert advice for the sepsis section.

\section{References}

1. General Dental Council. Scope of Practice. 2013 Available at https://www.gdc-uk.org/docs/defaultsource/scope-of-practice/scope-of-practice.pdf (accessed June 2020).

2. General Dental Council. Standards for the dental team. 2013. Available at https://standards.gdc-uk.org/Assets/ pdf/Standards\%20for\%20the\%20Dental\%20Team.pdf (accessed June 2020).

3. Müller M P, Hänsel M, Stehr S N, Weber S, Koch T. A state-wide survey of medical emergency management in dental practices: incidence of emergencies and training experience. Emerg Med J 2008; 25: 296-300.

4. Al-Turki O, Al-Hussyeen A, Al-Hammad N, Alhowaish L, Almaflehi N. Medical Emergencies In Dental Practice. J Dent Med Sci 2017; 16: 1-9.

5. Collange 0, Bildstein A, Samin J et al. Prevalence of medical emergencies in the dental practice. Resuscitation 2010; 81: 915-916.

6. Resuscitation Council (UK). Quality standards for cardiopulmonary resuscitation practice and training in primary dental care. 2017. Available online at https:// www.resus.org.uk/quality-standards/primary-dentalcare-quality-standards-for-cpr/ (accessed June 2020).

7. Greenwood M, Meechan J. General medicine and surgery for dental practitioners: part 2. Medical emergencies in dental practice: the drug box, equipment and basic principles of management. Br Dent 2014; 216: 633-637. 
8. Greenwood M. Medical Emergencies in Dental Practice: 1. The Drug Box, Equipment and General Approach. Dent Update 2009; 36: 202-211.

9. BNF. Medical emergencies in dental practice. 2020. Available online at https://b nf.nice.org.uk/guidance/ prescribing-in-dental-practice.html (accessed June 2020).

10. Jevon P. New poster to help manage medical emergencies. Br Dent J 2009; 207: 312

11. Jevon P. Updated guidance on medical emergencies and resuscitation in the dental practice. Br Dent J 2012; 212: $41-43$.

12. Jevon P. Updated posters to help manage medical emergencies in the dental practice. Br Dent J 2015; 219: 227-229.

13. Addison's Self-Help Group. Adrenal Crisis Can Kill. 2020. Available at https://www.addisonsdisease.org.uk/ emergency (accessed June 2020).

14. Specialist Pharmacy Service. What steroid supplementation is required for a patient with primary adrenal insufficiency undergoing a dental procedure? 2019. Available at https://www.sps.nhs.uk/articles/ what-steroid-supplementation-is-required-fora-patient-with-primary-adrenal-insufficiencyundergoing-a-dental-procedure/ (accessed June 2020).

15. NICE. Addison's disease - Scenario: Management. 2016 Available at https://cks.nice.org.uk/addisons-disease (accessed April 2020).

16. Department of Health \& Social Care. DHSC Supply Disruption Alert. 2018. Available at https://www.cas. mhra.gov.uk/ViewandAcknowledgment/ViewAlert. aspx?AlertID=102802 (accessed April 2020).

17. Medicines and Healthcare products Regulatory Agency. Drug Safety Update: Volume 13, Issue 3, October 2019. 2019. Available at https://assets.publishing. service.gov.uk/government/uploads/system/uploads/ attachment_data/file/840565/0ct-2019-PDF.pdf (accessed April 2020).

18. Office of Chief Dental Officer England. Adrenaline for anaphylaxis kits - a reminder to Health Care Professionals. 2018. Available at http://www.bsdht.org. uk/News/20181009\%20-\%20EpiPen\%20Advice\%20 $-\% 20$ CD0\%20England\%20Final.pdf (accessed April 2020).

19. Medicines and Healthcare products Regulatory Agency. Class 2 Medicines Recall: Emerade 300 micrograms solution for injection in pre-filled syringe, PL 33616/0013 (EL(20)A/14). 2020. Available online at https://www.gov.uk/drug-device-alerts/ class-2-medicines-recall-emerade-150-microgramssolution-for-injection-in-pre-filled-syringe-pl-336160013-el-20-a-14 (accessed June 2020).

20. Courts and Tribunals Judiciary. Regulation 28: Report to prevent further deaths. 2018. Available at https://www. judiciary.uk/wp-content/uploads/2018/10/NatashaLAPEROUSE-2018-0279.pdf (accessed June 2020).

21. Resuscitation Council (UK). Statement on Anaphylactic Guidelines. 2019. Available at https://www.resus.org uk/media/statements/statement-on-anaphylacticguidelines/ (accessed April 2020).

22. Resuscitation Council (UK). Anaphylaxis - Emergency treatment of anaphylactic reactions: guidelines for healthcare providers. 2012. Available online at https:// www.resus.org.uk/anaphylaxis/emergency-treatmentof-anaphylactic-reactions/ (accessed April 2020).

23. Public Health England. Immunisation against infectious disease. 2014. Available online at https://www.gov. uk/government/collections/immunisation-againstinfectious-disease-the-green-book (accessed April 2020).

24. Care Quality Commission. Dental mythbuster 4 Drugs and equipment for a medical emergency. 2019. Available at https://www.cqc.org.uk/guidanceproviders/dentists/dental-mythbuster-4-drugsequipment-medical-emergency (accessed April 2020).

25. Travers A, Taylor K. Adrenaline use: The use of pre-filled adrenaline syringes in anaphylaxis kits. Br Dent J 2019; 226, 85-86

26. Resuscitation Council (UK). Frequently asked questions (FAQs): Anaphylaxis treatment. 2014. Available at https://www.resus.org.uk/faqs/faqs-anaphylaxistreatment/ (accessed April 2020).
27. Ewan $\mathrm{P}$, Brathwaite N, Leech S et al. BSACl guideline: prescribing an adrenaline auto-injector. Clin Exp Allergy 2016; 46: 1258-1280.

28. NICE. Angio-ooedema and anaphylaxis. 2018. Available online at https://cks.nice.org.uk/angio-oedema-andanaphylaxis (accessed April 2020).

29. Asthma UK. Asthma death toll in England and Wales is the highest this decade. 2019. Available at https:// www.asthma.org.uk/about/media/news/pressrelease-asthma-death-toll-in-england-and-wales-isthe-highest-this-decade/ (accessed April 2020)

30. National Review of Asthma Deaths. Why asthma still kills. 2015. Available online at https://www.rcplondon. ac.uk/projects/outputs/why-asthma-still-kills (accessed April 2020).

31. British Thoracic Society. BTS/SIGN British Guideline on the Management of Asthma. 2019. Available online at https://www.brit-thoracic.org.uk/quality-improvement/ guidelines/asthma/ (accessed April 2020).

32. Medicines and Healthcare products Regulatory Agency. Drug Safety Update: Latest advice for medicines (Volume 11 Issue 12 July 2018). 2018. Available online at https://www.gov.uk/government/publications/ drug-safety-update-monthly-newsletter (accessed April 2020).

33. British Heart Foundation. Heart attack symptoms. 2020. Available at https://www.bhf.org.uk/ informationsupport/conditions/heart-attack/heartattack-symptoms (accessed April 2020).

34. SDCEP. Drug Prescribing for Dentistry: Dental Clinical Guidance (Third Edition). 2016. Available at https:// www.sdcep.org.uk/wp-content/uploads/2016/03/ SDCEP-Drug-Prescribing-for-Dentistry-3rd-edition.pdf (accessed June 2020).

35. British Heart Foundation. Bias and Biology: how the gender gap in heart disease is costing women's lives. 2020. Available online at https://www.bhf.org.uk/ informationsupport/heart-matters-magazine/medical/ women-and-heart-disease (accessed April 2020).

36. NICE. Chest Pain - Scenario: Management. 2020. Available at https://cks.nice.org.uk/chestpain\#!scenario (accessed April 2020).

37. British Heart Foundation. Heart attack. 2020. Available at https://www.bhf.org.uk/informationsupport/ conditions/heart-attack (accessed April 2020).

38. NICE. Epilepsies: diagnosis and management. 2020. Available at https://www.nice.org.uk/guidance/cg137 (accessed April 2020).

39. Great Ormond Street Hospital. Buccal (oromucosal) midazolam. 2017. Available online at https://www. gosh.nhs.uk/medical-information/medicinesinformation/buccal-oromucosal-midazolam (accessed April 2020).

40. Medicines and Healthcare products Regulatory Agency. Class 4 Medicines Defect Information: BUCCOLAM (midazolam) Oromucosal Solution Pre-filled Syringes. 2017. Available online at https://www.gov. uk/drug-device-alerts/class-4-medicines-defectinformation-buccolam-midazolam-oromuscosalsolution-pre-filled-syringes (accessed April 2020)

41. NICE. Type 1 diabetes in adults: diagnosis and management - NICE guideline (NG17). 2016. Available at https://www.nice.org.uk/guidance/ng17 (accessed April 2020).

42. Joint British Diabetes Societies for inpatient care. The Hospital Management of Hypoglycaemia in Adults with Diabetes Mellitus: 3rd edition. 2018. Available at http://www.diabetologists-abcd.org.uk/JBDS/ JBDS_HypoGuideline_FINAL_280218.pdf (accessed April 2020).

43. HM Treasury and HM Revenue \& Customs. The Soft Drinks Industry Levy. 2016. Available online at https:// www.gov.uk/government/consultations/soft-drinksindustry-levy (accessed April 2020)

44. Care Quality Commission. Dental mythbuster 6: Storing Glucagon injection. 2018. Available at https://www. cqc.org.uk/guidance-providers/dentists/dentalmythbuster-6-storing-glucagon-injection (accessed April 2020).

45. Gilway D, Brown S J. Medical emergencies: Sepsis in primary dental care. Br Dent J 2016; 220: 278

46. Royal College of Nursing. RCN Bulletin: Life beyond sepsis (Issue no. 376 June 2019). 2019. Available online at https://www.rcn.org.uk/news-and-events/rcnmagazines/bul-376 (accessed April 2020).

47. Carter L, Lowis E. Death from overwhelming odontogenic sepsis: a case report. Br Dent J 2007; 203: 241-242.

48. NICE. Sepsis: recognition, diagnosis and early management - NICE guideline [NG51]. 2017. Available at https://www.nice.org.uk/guidance/ng51 (accessed April 2020).

49. Coelho C, Mead M. Sepsis: the applicability to dental care professionals. Br Dent J 2018; 225: 1078-1081

50. UK Sepsis Trust. Clinical Tools. 2020. Available online at https://sepsistrust.org/professional-resources/clinicaltools / (accessed April 2020).

51. NICE. Stroke and transient ischaemic attack in over $16 \mathrm{~s}$ : diagnosis and initial management - NICE guideline [NG128]. 2019. Available at https://www.nice.org.uk/ guidance/ng128 (accessed April 2020).

52. Stroke Association. Share the FAST message. Available at https://www.stroke.org.uk/what-is-stroke/whatare-the-symptoms-of-stroke/share-the-fast-message (accessed April 2020).

53. Jevon P. Basic Guide to Medical emergencies in the dental practice. 3rd ed. Oxford: Wiley Blackwell, 2021. [In press].

54. NHS Improvement. Patient Safety Alert: Risk of death and severe harm from failure to obtain and continue flow from oxygen cylinders (June 2018 progress update). 2018. Available online at https://www. england.nhs.uk/2018/01/failure-to-obtain-andcontinue-flow-from-oxygen-cylinders/ (accessed June 2020).

55. Jevon P. Management of oxygen therapy in the dental practice. Br Dent J 2019; 226: 569-573.

56. NHS Improvement. ACT Academy: SBAR communication tool - situation, background, assessment, recommendation. 2018. Available at https://improvement.nhs.uk/documents/2162/sbarcommunication-tool.pdf (accessed April 2020).

57. British Society for Disability and Oral Health. Guidelines for the Delivery of a Domiciliary Oral Healthcare Service. 2009. Available at http://www.wales.nhs. uk/documents/BSDH_Domiciliary_Guidelines_ August 2009.pdf (accessed April 2020).

58. Care Quality Commission. Dental mythbuster 24 Medical resuscitation equipment for domiciliary dental care. 2018. Available at https://www.cqc.org.uk/ guidance-providers/dentists/dental-mythbuster-24medical-resuscitation-equipment-domiciliary-dental (accessed April 2020).

59. Department of Health. Health and Social Care Act. Code of practice on the prevention and control of infections. 2015. Available at https://assets. publishing.service.gov uk/government/uploads/system/uploads/attachment data/file/449049/Code_of_practice_280715_acc.pdf (accessed April 2020).

60. Care Quality Commission. Dental mythbuster 9: Hand hygiene. 2018. Available at https://www.cqc.org.uk/ guidance-providers/dentists/dental-mythbuster-9hand-hygiene (accessed April 2020).

61. Public Heath England. COVID-19: infection prevention and control guidance. 2020. Available at https:// assets.publishing.service.gov.uk/government/uploads/ system/uploads/attachment_data/file/886668/COVID 19_Infection_prevention_and_control_guidance_ complete.pdf (accessed May 2020).

62. Resuscitation Council (UK). Statements on COVID-19 (Coronavirus), CPR and Resuscitation. 2020. Available online at https://www.resus.org.uk/media/statements/ resuscitation-council-uk-statements-on-covid-19coronavirus-cpr-and-resuscitation/ (accessed April 2020).

63. General Dental Council. Enhanced CPD Scheme 2018 2018. Available online at https://www.gdc-uk.org/ education-cpd/cpd/enhanced-cpd-scheme-2018 (accessed April 2020).

64. General Dental Council. Recommended CPD topics. Available at https://www.gdc-uk.org/education-cpd/ cpd/recommended-cpd-topics (accessed April 2020).

65. Care Quality Commission. Dental mythbuster 2: Keeping up to date for the dental practice team. 2018. Available at https://www.cqc.org.uk/guidance-providers/ dentists/dental-mythbuster-2-keeping-date-dentalpractice-team (accessed April 2020). 